\title{
A RESPONSABILIDADE CIVIL COMO INSTRUMENTO DE CORREÇÃO DE INJUSTIÇAS NO CASO DE VIOLAÇÃO À PROTEÇÃO DE DADOS PELA FUNÇÃO JURISDICIONAL
}

\author{
CIVIL RESPONSIBILITY AS A WAY TO CORRECT \\ INJUSTICES IN CASE OF VIOLATION TO DATA \\ PROTECTION BY THE JUDICIARY
}

DANÚbia Patrícia De PAIVA ${ }^{1}$

\section{RESUMO}

É assente na doutrina clássica e na jurisprudência que apenas nas hipóteses previstas na legislação específica e na Constituição Federal é admitida a responsabilidade civil do Estado que decorre da função jurisdicional. Todavia, reconhecido que a proteção de dados pessoais é direito fundamental, deve-se conjecturar a responsabilidade do Estado em relação aos atos judiciais para além dessas hipóteses. 0 Judiciário busca se adequar, a partir da tecnologia, para o desenvolvimento de sua atividade. Ao mesmo tempo, todavia, precisa preservar a privacidade dos cidadãos. Trata-se de uma realidade complexa que deve ser entendida pelos operadores do Direito, buscando-se a melhor interpretação normativa a atender ao interesse público e à proteção de dados.

PALAVRAS-CHAVE: Responsabilidade civil do Estado. Proteção de Dados Pessoais. Judiciário.

\section{ABSTRACT}

In the doctrine and jurisprudence, only in cases provided for in specific legislation and in the Federal Constitution, is the State's civil liability arising from the jurisdictional function allowed. However, as the protection of personal data is a fundamental right, one must think about the State's responsibility in relation to judicial acts beyond these assumptions. The Judiciary seeks to adapt itself, by technology, for the development of

1 Advogada e Professora. Doutora em Direito Processual Civil pela Universidade PUC/MINAS (2020). Mestre em Direito Público pela Universidade FUMEC (2015). Graduada em Direito pela UFMG (2007) e em Gestão Pública e Direito Administrativo pelo UNI/BH (2004). Possui Pós-graduação Lato Sensu em Direito Processual Civil pela UNIDERP (2010) e em Direito do Estado pela Universidade Cândido Mendes (2019). Professora na Escola Superior de Advocacia da OAB, na Universidade FUMEC e na Faculdade ALIS. Produtora de conteúdo sobre Direito Digital na página @direitonoponto do Instagram. ORCID iD: https://orcid.org/0000-0003-1247-5882. E-mal: 
its activity. At the same time, it needs to preserve citizens' privacy. It is a complex reality, which needs to be understood by the operators of the law, seeking the best interpretation of the law to meet the public interest and data protection.

KEYWORDS: State civil liability. Protection of Personal Data. Judiciary.

\section{INTRODUÇÃO}

A questão relativa ao armazenamento, compartilhamento e divulgação de dados pessoais é de essencial interesse dos Estados. Por isso, muitas leis surgiram com a finalidade de regulamentação da matéria.

No Brasil, recentemente, criou-se a Lei de n. 13.709/2018, mais conhecida como Lei Geral de Proteção de Dados Pessoais (LGPD). Segundo o artigo $1^{\circ}$ da LGPD, a lei tem o objetivo de "proteger os direitos fundamentais de liberdade e de privacidade e o livre desenvolvimento da personalidade da pessoa natural" (BRASIL, 2018).

Há outras normas e princípios constitucionais que igualmente tratam do tema. A Lei de Acesso à Informação (Lei no 12.527), o Lei do Marco Civil da Internet (Lei n 12.965), o Código de Defesa do Consumidor, e entre outras, prevalecendo em todas elas a orientação de que devem ser vislumbradas restrições no tratamento de dados pessoais, bem como maior controle no uso desses.

A utilização dos dados pessoais impõe a ideia de vigilância e segurança, sendo relevante considerar as consequências jurídicas que podem advir diante de vazamentos ou má utilização dos dados pessoais.

O Judiciário, no exercício da função jurisdicional, tem acesso a diversas espécies de dados pessoais. São documentos de identidade, CPF, passaporte, título de eleitor e outros extremamente sensíveis.

0 artigo $5^{\circ}$, inciso II da LGDP prevê que dado pessoal sensível é todo dado pessoal sobre origem racial ou étnica, convicção religiosa, opinião política, filiação a sindicato ou à organização de caráter religioso, filosófico ou político, dado referente à saúde ou à vida sexual, dado genético ou biométrico, quando vinculado a uma pessoa natural. Trata-se de espécies de dados que abrem margem para discriminação, podendo ser utilizados para prejudicar de alguma maneira as pessoas, criando preconceitos (BRASIL, 2018).

A problemática, contudo, está na acessibilidade destes dados por terceiros, na medida em que ao se tornarem públicos pelos processos, podem ser utilizados para despertar ações preconceituosas, podendo violar a dignidade da pessoa humana, por vezes de forma definitiva, permitindo discriminação (FRAZÃO, p.34, 2019).

O Judiciário convive, portanto, com um grande desafio: o de informar toda a sociedade dos processos judiciais e julgamentos e, ao mesmo tempo, o de preservar a privacidade dos jurisdicionados.

No que se refere à responsabilidade e ao ressarcimento por violação às normas de proteção de dados, o artigo 42 da LGPD traz a previsão de que o controlador ou operador dos 
dados que, em sua atividade, causar dano a outrem, está obrigado a repará-lo, o que é traduz uma "repetição" da regra geral de responsabilização do Código Civil (arts. 186 e 927) (BRASIL, 2002).

Diante disso, nota-se que a LGPD é genérica, não mencionando, de forma expressa, como a lei deve ser aplicada aos serviços do Judiciário.

O presente artigo vem tratar deste tema, considerando a possibilidade de responsabilidade civil do Estado na hipótese de dano grave provocado pelo Judiciário em razão de violação às normas de proteção de dados.

O Supremo Tribunal Federal (STF), no julgamento da Medida Cautelar nas Ações Diretas de Inconstitucionalidade n. 6387, 6388, 6389, 6393, 6390, proferiu decisão histórica, ao reconhecer, expressamente, o direito fundamental à proteção de dados pessoais, ao suspender a aplicação da Medida Provisória 954/2018, que obrigava as operadoras de telefonia a repassarem ao IBGE dados identificados de seus consumidores de telefonia móvel, celular e endereços (BRASIL, 2020).

Os Ministros do STF, antes mesmo da inclusão deste direito no texto constitucional, já consideram a proteção de dados pessoais como um direito fundamental autônomo, que se diferencia da proteção à intimidade e privacidade, uma vez que o objeto protegido é distinto².

A importância do direito fundamental à proteção de dados pessoais e a influência atual do Judiciário no contexto social brasileiro são determinantes para ressaltar a relevância da responsabilização, garantindo, a aqueles afetados pela prestação jurisdicional, o direito ao ressarcimento, considerando os objetivos e os fundamentos da República Federativa do Brasil e do Estado Democrático de Direito.

O Estado tem como dever indenizar todo aquele que, por ato ou omissão, sofrer prejuízos. Assim, é essencial perquirir uma forma de compatibilizar a função judicial, a proteção de dados pessoais e o direito ao ressarcimento no caso de dano.

Nesse ponto, é um desafio adequar as regras da proteção de dados com o interesse público e o acesso à justiça, sobretudo porque, como já ressaltado, o Judiciário também se utiliza de dados sensíveis, sujeitos a condições especiais de tratamento.

Para analisar a problemática acima identificada, considerou-se, como referencial teórico, obras e artigos científicos, bem como questões pragmáticas, principalmente diante do pouco desenvolvimento teórico e inédito sobre o tema.

Em linhas introdutórias, a expectativa é que este estudo seja útil à comunidade jurídica e à sociedade, delimitando o assunto e aprofundando nas questões centrais, a fim de contribuir para a construção de uma análise conforme os ditames do Estado Democrático de Direito.

2 Para outras informações acerca dos vícios de inconstitucionalidade suscitados da MP 954, há um artigo no Jota: Disponível em https://www.jota.info/opiniao-e-analise/artigos/a-encruzilhada-da-protecao-de-dados-no-brasil-e-o-caso-do-ibge-23042020. Acesso em 04 mar. 2020. 


\section{O PROBLEMA DA IRRESPONSABILIDADE DO ESTADO NO EXERCÍCIO DA FUNÇÃO JURISDICIONAL}

O Código de Processo Civil de 2015, no artigo 143, I e a Lei Complementar n. 35/1979 (Lei Orgânica da Magistratura Nacional), no artigo 49, I, prescrevem que o magistrado responderá por perdas e danos quando, no exercício de suas funções, proceder com dolo ou fraude (BRASIL, 2015).

Ademais, nos termos do inciso II do artigo 143 do CPC, caso recuse, omita ou retarde, sem justo motivo, providência que deva ordenar de ofício ou a requerimento da parte, também pode o juiz vir a ser responsabilizado. Contudo, essas hipóteses somente serão verificadas depois que a parte requerer ao juiz que determine a providência e o requerimento não for apreciado no prazo de 10 (dez) dias (BRASIL, 2015).

Já a Constituição da República prevê a responsabilização do Estado pelo erro judiciário e prisão além do tempo fixado na sentença, conforme artigo 5², inciso LXXV (BRASIL, 1988).

Em hipóteses diversas das apresentadas acima, na doutrina clássica e na jurisprudência, a regra é a da irresponsabilidade do Estado, a partir de vários argumentos empregados.

Os adeptos da tese da irresponsabilidade, argumentam, primeiramente, que as decisões judiciárias estão sujeitas a recurso.

Assim, disponibilizado à parte referido instrumento para que esta se proteja das "injustiças" cometidas no processo, seria dispensável a discussão, em outra ação, da decisão ou de eventual responsabilidade judicial.

0 argumento empregado é o de que as decisões judiciárias são normalmente sujeitas a recurso e que o recurso constitui exatamente o instrumento regular e suficiente das partes para protegerem-se contra injustiça judiciária (CAPELLETTI, 1989, p. 27).

Todavia, deve-se observar que o recurso não se apresenta como meio hábil a permitir às partes a possibilidade plena de instrução probatória, disponível na hipótese de uma ação judicial de responsabilidade civil.

Além disso, o recurso pode não reformar uma decisão eventualmente irregular e, quando não mais cabível, irá permitir que esta, já com o caráter de coisa julgada, não mais seja passível de discussão. Sobre a questão, Cappelletti também ressalta:

Mas, uma vez que a decisão do juiz, não mais se sujeita a recurso, torna-se definitiva, adquire a autoridade de coisa julgada [...]. Ainda que, por hipótese, errônea de fato ou de direito, a decisão passada em julgado cria a sua própria "verdade" e o seu próprio direito; ela facit jus. E a conclusão é que a responsabilidade civil sequer pode ser reconhecida, dado que dita responsabilidade pressupõe o ato contrário ao direito, o "damnuminiuriadatum", iniuria que, por princípio, não pode derivar da decisão que facit jus." (CAPELLETTI, 1989, p. 27).

Argumenta-se, ainda, a irresponsabilidade judicial absoluta porque o ato do juiz é considerado ato do Estado, protegido pelo princípio da legitimidade, verificando-se uma acentuada relação de dependência dos juízes perante o Executivo (CAPELLETTI, 1989, p. 25). 
Entretanto, o princípio da presunção de legitimidade, presente nos atos estatais, não se mostra idôneo para afastar a responsabilidade civil em relação aos atos judiciais, já que, há muito, abandonou-se o princípio da irresponsabilidade geral do Estado no exercício de atividades.

Observa-se que há outro argumento, apresentado por Mauro Capelletti, também historicamente empregado para afastar a responsabilidade, qual seja, o de autoridade da coisa julgada nas decisões judiciais.

A força do princípio da coisa julgada, em particular, não está nos ditames de uma lógica abstrata, mas apenas nos fins ou valores que os sistemas jurídicos intentem perseguir mediante aquele princípio. É geralmente reconhecido que tal fim ou valor se encontra na paz social e na certeza do direito: a decisão judiciária, prescindindo do fato de que seja ou não correta (de fato e de direito). , deve em determinado ponto dar fim ao litígio" (CAPELLETTI, 1989, p. 29).

O princípio da coisa julgada (res judicata facit jus) tem relação com a ideia de soberania do poder estatal, o que mais especificamente se revela na tese de independência dos juízes (CAPELLETTI, 1989, p. 24).

Contudo, no modelo "responsive", que não admite a sua negação total, há um esforço "em realizar o equilíbrio entre independência e responsabilidade-controle social, com o fim de evitar, ao mesmo tempo, a sujeição e igualmente o fechamento e o isolamento da magistratura" (CAPELLETTI, 1989, p. 10).

Nestes termos, a premissa é a seguinte: onde há poder deve haver responsabilidade.

Assim, em uma sociedade organizada racionalmente, há uma relação diretamente proporcional entre poder e responsabilidade. Os juízes exercitam um poder. E "um poder não sujeito a prestar contas representa patologia" (CAPELLETTI, 1989, p. 18).

[...] parece fora de dúvida que um sistema de governo liberal-democrático - um sistema, pois, que queira garantir as liberdades fundamentais do indivíduo em um regime de democracia social, como é previsto na Constituição Italiana - é sobretudo aquele em que exista razoável relação de proporcionalidade entre poder público e responsabilidade pública, de tal sorte que ao crescimento do próprio poder corresponda um aumento dos controles sobre o exercício de tal poder. Esta correlação é inerente ao que se costuma chamar de sistema de pesos e contrapesos, checksand balances (CAPELLETTI, 1989, p. 18).

Prosseguindo nesta análise, deve-se considerar que a "imunidade" dos juízes, prevista em praticamente todos os ordenamentos jurídicos, constitui um problema de equilíbrio entre os valores garantia e independência, conforme demonstrado por Mauro Capelletti:

[...] o problema da imunidade dos juízes é, mais precisamente, o problema - menos absoluto e mais pragmático, de limites da responsabilidade, vale dizer, um problema de equilíbrio entre o valor de garantia e instrumental da independência, externa e interna dos juízes, e o outro valor moderno (mas também antigo, como se viu). do dever democrático de prestar contas (CAPELLETTI, 1989, p. 33).

Ao citar TROCKER, o referido autor ressalta o seguinte: 
Como escreveu Trocker, [...] "o privilégio da substancial irresponsabilidade do magistrado não pode constituir o preço que a coletividade é chamada a pagar, em troca da independência dos seus juízes" (CAPPELLETTI, 1989, p. 33).

Por essas razões, vê-se que a imunidade e a independência devem ser vistas não como conceitos capazes de anular os valores democráticos, a exemplo do que já ocorre em relação à responsabilidade de outros agentes que exercitam o poder público.

A singular função jurisdicional não pode ser pretexto para a irresponsabilidade, em especial à luz do Estado Democrático de Direito.

Não pode sustentar a irresponsabilidade estatal no fato de ser o exercício da função judiciária uma 'manifestação da soberania' (seria justificá-la na máxima regalengathe king can do no wrong). A idéia de soberania não se contrapõe à de responsabilidade do Estado, que também se submete ao Direito. Por outro lado, se se admitisse o argumento, o Estado também seria irresponsável por atos do Executivo, o que, hoje, não mais se admite (seja na doutrina seja na jurisprudência) (DERGINT, 1994, p. 227).

O Judiciário tem a missão tradicional de aplicar a lei ao caso concreto, controlar os demais "poderes", proteger os direitos fundamentais e garantir o Estado Constitucional Democrático de Direito.

O modelo de irresponsabilidade diante de atos judiciais não coaduna com os princípios da Constituição da República.

Se por um lado é certo que o Estado não deve responder indiscriminadamente em hipóteses nas quais não contribuiu de qualquer modo para o advento do dano; por outro, não se pode negligenciar o fato de que sua atuação tem como pressuposto a proteção e o respeito aos direitos da coletividade, tornando inadmissível sua irresponsabilidade nos casos em que esta sirva como instrumento de perpetuação de injustiças e de violação dos princípios fundamentais do Direito (SILVA, p. 11, 2002).

Portanto, é essencial a criação de um modelo de responsabilidade jurídica, que encontre equilíbrio entre a independência assegurada à carreira de magistrado e a responsabilidade pelo exercício de uma função estatal.

\section{A RESPONSABILIDADE CIVIL COMO INSTRUMENTO DE CORREÇÃO DE INJUSTIÇAS NO CASO DE VIOLAÇÃO À PROTEÇÃO DE DADOS PELA FUNÇÃO JURISDICIONAL}

Dentre os direitos fundamentais garantidos pela Constituição da República está o acesso à justiça.

Para Mauro Cappelletti e Bryant Garth, o acesso à justiça é "o requisito fundamental - o mais básico dos direitos humanos - de um sistema jurídico moderno e igualitário que pretenda garantir, e não apenas proclamar os direitos de todos" (CAPPELLETTI, 1988, p. 12). 
A partir do exposto, é possível concluir que o impedimento doutrinário de responsabilização pela via judicial viola o acesso à justiça, sendo abusivo impedir que lesões às esferas jurídicas dos cidadãos por atos judiciais sejam passíveis de ressarcimento.

Cumpre ressaltar que, em relação aos atos estatais exarados pelo Executivo, aplica-se, sem ressalvas, a denominada Teoria da Responsabilidade Objetiva do Estado, prevista na Constituição de 1988, no $\S 6^{\circ}$ do art. 37.

Art. 37. A administração pública direta e indireta de qualquer dos Poderes da União, dos Estados, do Distrito Federal e dos Municípios obedecerá aos princípios de legalidade, impessoalidade, moralidade, publicidade e eficiência e, também, ao seguinte: (Redação dada pela Emenda Constitucional $n^{\circ}$ 19, de 1998).

[...]

$\S 6^{\circ}$ - As pessoas jurídicas de direito público e as de direito privado prestadoras de serviços públicos responderão pelos danos que seus agentes, nessa qualidade, causarem a terceiros, assegurado o direito de regresso contra o responsável nos casos de dolo ou culpa (BRASIL, 1988).

Segundo referido dispositivo, as pessoas jurídicas de direito público têm responsabilidade objetiva por danos causados por seus agentes.

A responsabilidade objetiva do Estado representa a obrigação do Estado de indenizar, independentemente de culpa, no exercício de suas atividades (funções), os danos ocasionados por quaisquer de seus agentes, em decorrência de comportamentos unilaterais, lícitos ou ilícitos, comissivos ou omissivos, materiais ou jurídicos, respeitadas as excludentes legais e futuro direito de regresso.

Neste ponto, vale ressaltar que os atos considerados funcionais, administrativos, atípicos à função de julgar, como por exemplo, medidas tomadas para administração e funcionamento do Judiciário, se significarem dano a terceiros, de maneira assente na doutrina e jurisprudência nacional, podem gerar a responsabilidade objetiva do Estado, nos termos do art. $37, \S 6^{\circ}$ da Constituição de 1988 (BRASIL, 1988).

A responsabilidade do Estado se restringe aos danos causados por funcionários administrativos, nessa qualidade, a terceiros; não responde o Estado por possíveis danos, oriundos de decisões ou atos judiciais errados, segundo a doutrina já aceita e consagrada pela jurisprudência dos tribunais (STOCO, 1996, p. 414).

Para além dos atos de natureza administrativa, alguns doutrinadores defendem que, apesar de ser possível a responsabilização estatal, esta seria cabível apenas nos casos expressos em lei, como já registrado no presente artigo.

Yussef Cahali, todavia, repudia tal argumento:

Não procede o argumento de que o Estado somente responde por atos judiciais nas hipóteses expressamente declaradas em lei, que, assim, representariam exceções a uma pretensa imunidade do Estado - igualmente sem correspondência legal. De qualquer forma, o princípio da responsabilidade estatal encontra-se consagrado, textualmente, em regra constitucional (art. 37, § 6. ․, CF/1988 (LGL\1988\3)), aplicável aos atos danosos executivos, legislativos e judiciais. Não se pode dizer que existe uma lacuna no sistema jurídico. Mesmo se houvesse, ela não eximiria o juiz de julgar, devendo ele 
recorrer à analogia, aos costumes e aos princípios gerais do direito (CAHALI, 2007, p. 512).

Apesar da presente discussão não ser nova, observa-se que a responsabilidade civil em face de danos decorrentes de atos do Judiciário ainda não foi acolhida pela legislação ou mesmo pelo próprio Judiciário, conforme salienta Marcus Paulo Queiroz Macedo.

Como adverte Augusto do Amaral Dergint (1994, p. 225), "é impossível falar sobre a responsabilidade estatal por atos judiciais sem polemizar", uma vez que "a doutrina brasileira dominante defende a tese da responsabilidade; no entanto, ela ainda está no plano puramente teórico, porque não foi acolhida quer no âmbito da legislação, quer no âmbito do Poder Judiciário" (DI PIETRO, 1994, p. 86). No mesmo sentido, aduz Ruy Rosado do Aguiar Júnior (1993, p. 6): "a idéia da responsabilidade estatal por ato jurisdicional pouco avançou na lei e na aplicação dos Tribunais, apesar do hoje majoritário apoio da doutrina, preponderantemente favorável à sua plena incidência". Com efeito, esta responsabilização já é defendida há muito no país, tendo por posições seminais as de Juary C. Silva (1965), José Cretella Jr. (1970) e Aguiar Dias, o qual, ainda sobre a égide da Constituição de 1946, afirmou (2006, p. 864): "Qualquer que seja o papel do Judiciário, o certo é que os Juízes são servidores do Estado e agem em seu nome. E a Constituição, ao cogitar da responsabilidade do Estado não permite indagação senão sobre a relação de causalidade entre o dano e o serviço público, não devendo haver privilégio para impunidade de um dano causado por ato classificado pelo próprio Judiciário como ilegalidade manifesta" (MACEDO, 2008, p. 229).

Contudo, verifica-se que a não adoção da teoria da responsabilidade estatal é ainda mais grave atualmente, em que se nota um papel central do Judiciário, considerado como protagonista do cenário político e social, e diante da inclusão da tecnologia a serviço do Judiciário.

Paralelamente à maior participação do Judiciário, surgiu a implementação do processo em meio eletrônico, a intensificar cada vez mais a utilização da tecnologia para a manutenção das atividades jurisdicionais.

Sem se deslocar de seu escritório, pode o advogado, a partir de cadastro realizado junto ao Judiciário, ajuizar ações, realizar consulta de peças processuais, se manifestar e receber intimações.

Neste caso, os advogados precisam se cadastrar, pessoalmente, nos sistemas judiciais eletrônicos, "momento em que criarão um identificador e uma senha de acesso ao sistema, bem como criarão uma assinatura digital, a qual possibilitará a realização dos atos processuais com a máxima segurança, máxima autenticidade e máxima celeridade" (CARVALHO, 2010).

A virtualização do procedimento judicial também se verifica em outras situações, como por exemplo, na "telessustentação" ou sustentação oral à distância. Nesse "telecomparecimento", o advogado acompanha a sessão de julgamento à distância, nela intervindo, mesmo que não tenha fisicamente comparecido.

Contudo, em tempos de "big data", não há dúvida de que, todos aqueles que possuem bancos de dados de informações de outras pessoas, tem o dever de promover formas de controle, tutela e adequado gerenciamento desses dados, a fim de não comprometerem direitos dos cidadãos. 
O termo "Big Data" descreve não só a tecnologia apropriada para a captura de dados, como também o crescimento, a disponibilidade e o uso exponencial de informações estruturadas e não estruturadas que circulam pela Internet (SIMÃO FILHO; SCHWARTZ, 2018, p. 217).

A existência de plataformas de base tecnológicas de geração, recepção e transmissão de dados que serão processados, analisados e transformados em algoritmos é um fenômeno que funciona como base neste conceito de Big Data, a caracterizar a Quarta Revolução Industrial.

Pelo menos duas revoluções tecnológicas estão diretamente ligadas ao gênero do que se convencionou denominar de quarta revolução industrial, qual seja: a revolução dos negócios baseados em dados decorrente da constatação e utilização de novas fontes de dados gerados por meios sociais e pelo crescimento da telefonia móvel e sistemas digitais diversificados de captação da informação e imagens, com potencial para modificar por completo o processo tradicional de geração de valor de uma companhia. A boa aglutinação destes dados, em uma base digital adequada, pode gerar conhecimentos adicionais sobre o interesse, as paixões as afiliações, redes e relações do usuário, além de elementos de fidelização de tal ordem que se otimize ao infinito o processo de captação e prospecção de clientela, e a outra revolução decorrente da implantação da Internet das Coisas (SIMÃO FILHO; SCHWARTZ, 2018, p. 224-225).

Neste ponto, há questão essencial a ser considerada, qual seja, a privacidade do cidadão, sobretudo diante das constantes preocupações quanto à sua violação com a evolução da sociedade da informação. Sobre essa nova realidade, defende Laura Schertel Mendes:

Em uma sociedade conectada, a proteção de dados não é mais um direito entre tantos, mas um elemento essencial para a manutenção da confiança dos cidadãos nas estruturas de comunicação e informação, bem como para o necessário fluxo de dados e inovação dele decorrente. Como regulação de uma ordem comunicacional e informacional, que é por definição multidimensional, a proteção de dados tem como objetivo equilibrar os direitos de proteção, de defesa e de participação do indivíduo nos processos comunicativos (MENDES, 2020).

A proteção da personalidade na sociedade digital deve considerar, ainda, a capacidade de desenvolvimento interacional do indivíduo, isto é, a capacidade de progresso da pessoa humana, que apenas se desenvolve por meio de outras pessoas, o que reforça a necessidade de proteção da privacidade.

De um lado, contudo, há uma preocupação com a defesa da privacidade dos indivíduos, travando-se intensas discussões sobre vazamentos de dados, públicos e privados; de outro, há a necessidade de se verificar a existência de interesse público relacionado àquele cidadão, relevante para a comunidade.

Assim, como compatibilizar o interesse público das informações processuais com o direito à privacidade?

Inicialmente, deve-se ter em mente que também o Judiciário deverá atender à Lei Geral de Proteção de Dados (LGPD) (BRASIL, 2018). 
A referida lei dedica um capítulo com nove artigos (Capítulo IV) exclusivamente para abordar o tema "Tratamento de Dados Pessoais pelo Setor Público", indicando a integração com a Lei de Acesso à Informação.

Assim sendo, da mesma forma que as instituições privadas devem observar uma finalidade específica para a realização do tratamento de dados pessoais, também a pessoa jurídica de direito público deve adotar a finalidade pública e o interesse público específicos para a realização de tratamento de seus dados.

Verifica-se, então, que caberá ao Judiciário a garantia de que o uso dos dados segue os propósitos especiais que concernem à execução das funções daquele órgão e, ao mesmo tempo, a ponderação entre a necessidade da publicidade das informações e os direitos dos titulares.

Os artigos 25, 26 e 27 da LGPD encarregam-se de descrever como e quando pode ocorrer o compartilhamento dos dados pessoais geridos pelo setor público. (BRASIL, 2018)

Os dados deverão ser mantidos em formato interoperável e estruturado para o uso compartilhado, com vistas à propósitos legítimos, expressos e previamente definidos, quais sejam, execução de políticas públicas, prestação de serviços públicos, descentralização da atividade pública e de disseminação e ao acesso das informações pelo público em geral.

Em regra, a transferência dos dados pessoais às entidades privadas é vedada. A ressalva ocorre nas situações em que os dados são acessíveis publicamente; quando houver previsão legal ou a transferência for respaldada em contratos, convênios ou instrumentos congêneres; ou que a execução de um serviço ou medida o exigir. Excepciona-se também na hipótese de a transferência dos dados objetivar, exclusivamente, a prevenção de fraudes e irregularidades, ou proteger e resguardar a segurança e a integridade do titular dos dados, desde que vedado o tratamento para outras finalidades.

0 artigo 27 determina ainda que deve existir consentimento do proprietário dos dados para que eles possam ser compartilhados entre a Administração Pública e algum ente privado, com algumas exceções (BRASIL, 2018).

Já o artigo 31, prevê que os órgãos públicos estão sujeitos às medidas administrativas específicas; em virtude disso, cabe à autoridade nacional garantir que medidas cabíveis e proporcionais sejam adotadas quando da violação do tratamento de dados pessoais nos órgãos públicos (BRASIL, 2018).

Completa essa ideia a determinação do artigo 32, que anuncia a necessidade de as instituições públicas preverem o impacto de privacidade no âmbito da administração pública, o que por certo terá grande consequência, pois exigirá diversas políticas públicas para adequação e conformidade do setor público à nova regulamentação (BRASIL, 2018).

A partir da lei, vê-se também que as sanções administrativas a que se submetem os entes públicos são mais brandas do que aquelas a que se submetem os entes privados, sendo estabelecidas no $\S 3^{\circ}$ do artigo 52. De um exame do referido artigo, embora não se tenha a punição de multa para entidades públicas, sanções como o bloqueio dos dados pessoais podem causar grande impacto na atuação pública (BRASIL, 2018). 
Feitas essas considerações, não há dúvida de que o Judiciário deverá respeitar a LGPD, sob pena de se criar uma legislação eficaz apenas para o setor privado, sem observância para o setor público, que possui o maior volume de dados armazenados.

A partir disso, o Conselho Nacional de Justiça criou, através da Portaria 63/2019, um grupo de trabalho destinado a elaborar estudos e propostas sobre políticas de acesso às bases de dados processuais dos tribunais, em especial quando há finalidades comerciais. Segundo o ministro Dias Toffoli, a preocupação principal é com "a cautela que se deve guardar quanto ao acesso irrestrito a informações relevantes sobre o cidadão" (RACANICCI, 2019).

Na mesma linha dos outros "poderes", o CNJ publicou, após a realização desses estudos prévios, a Recomendação 73/2020, com orientações para adequação de todos os órgãos do Judiciário, instituindo um padrão nacional de proteção de dados pessoais existentes nas suas bases (BRASIL, 2020).

Sobre a importância da regulação deste tema, são as orientações de Yuval Noah Harari:

Assim, faríamos melhor em invocar juristas, políticos, filósofos e mesmo poetas para que voltem sua atenção para essa charada: como regular a propriedade de dados? Essa talvez seja a questão política mais importante da nossa era. Se não formos capazes de responder a essa pergunta logo, nosso sistema sociopolítico poderá entrar em colapso (HARARI, p. 110-111).

O processo jurisdicional é público por força do disposto no inciso LX do artigo $5^{\circ}$ dispõe que: "a lei só poderá restringir a publicidade dos atos processuais quando a defesa da intimidade ou o interesse social o exigirem" (BRASIL, 1988).

Essa publicidade acaba alcançando também os dados pessoais que possam constar nas ações judiciais, que, em razão do artigo $7^{\circ}, \S^{\circ}$, da Lei Geral de Proteção de Dados Pessoais são tornados manifestamente públicos por seus titulares (BRASIL, 2018).

Por tal razão, há dificuldade para mensurar os impactos decorrentes do exercício da função jurisdicional em relação à proteção de dados, principalmente no que se refere à abrangência dos danos passíveis de serem verificados, bem como em relação à ilicitude da conduta estatal.

Entretanto, é certo que eventual criação de embaraços e constrangimentos burocráticos - ou mesmo a restrição da consulta aos processos pelas partes - não vai eliminar riscos de vazamentos e o acesso a documentos pessoais.

Apesar disso, importa destacar que, em relação aos processos jurisdicionais, não há dúvida de que o Estado e a sociedade podem ter direito, como regra geral, ao conhecimento do "outro", mas somente se houver necessidade. Do contrário, é preciso preservar ao máximo a privacidade dos cidadãos, em observância à tutela constitucional da intimidade e proteção dos dados.

A exposição dos dados pessoais precisa ser medida, a fim de permitir o controle dos atos jurisdicionais e atender ao princípio da publicidade, sem se tornar excessiva, a ponto de configurar exposição sensacionalista ou sem propósito.

Neste ponto, cumpre trazer algumas considerações de Laura Mendes sobre a tutela constitucional do direito à proteção de dados: 


\begin{abstract}
Avançando, então, em seus contornos, pode-se dizer que o direito fundamental à proteção de dados enseja tanto um direito subjetivo de defesa do indivíduo (dimensão subjetiva), como um dever de proteção estatal (dimensão objetiva). Na dimensão subjetiva, a atribuição de um direito subjetivo ao cidadão acaba por delimitar uma esfera de liberdade individual de não sofrer intervenção indevida do poder estatal ou privado. A dimensão objetiva representa a necessidade de concretização e delimitação desse direito por meio da ação estatal, a partir da qual surgem deveres de proteção do Estado para a garantia desse direito nas relações privadas. Isso significa que os atos do Estado passam a ser controlados tanto por sua ação, como também por sua omissão (MENDES, 2020).
\end{abstract}

Ademais, é possível que a exposição possa causar dano significativo ao titular dos dados, o que precisa ser conjecturado e analisado, segundo as normas do ordenamento jurídico já existentes, considerando, ainda, uma interpretação coerente com o Estado Democrático de Direito.

No que tange à responsabilidade civil e ao ressarcimento, o artigo 42 da LGPD traz a previsão de que controlador ou operador dos dados que, em sua atividade, causar dano a outrem, está obrigado a repará-lo. Os agentes de tratamento só não serão responsabilizados quando provarem: que não realizaram o tratamento de dados pessoais que lhes é atribuído; que, embora tenham realizado o tratamento de dados pessoais que lhes é atribuído, não houve violação à legislação de proteção de dados; ou que o dano é decorrente de culpa exclusiva do titular dos dados ou de terceiro (art. 43) (BRASIL, 2018).

A LGPD, em seu artigo $6^{\circ}$, prevê ainda o princípio da responsabilização e prestação de contas, ficando registrado ser ônus do agente demonstrar a adoção de medidas eficazes e capazes de comprovar o cumprimento das normas de proteção de dados pessoais e a sua eficácia. Se não demonstrar, no caso de danos decorrentes de violação de segurança dos dados, responderá aquele que, ao deixar de adotar as medidas de segurança previstas no art. 46 da mesma lei, der causa aos danos (BRASIL, 2018).

Sobre o dever de observar a legislação de proteção de dados e de segurança, o artigo 44 é claro ao expor que o tratamento de dados pessoais será irregular a considerar algumas circunstâncias relevantes, entre as quais, o modo pelo qual é realizado; o resultado e os riscos que razoavelmente dele se esperam; as técnicas de tratamento de dados pessoais disponíveis à época em que foi realizado (BRASIL, 2018).

Nota-se que os dispositivos da LGPD são gerais, não mencionando expressamente como a lei deve ser aplicada aos serviços do Judiciário. Trata-se de mera repetição da regra geral de responsabilização civil do Código Civil, presente nos artigos 186 e 927 (BRASIL, 2002).

Neste ponto, ao não tratar especificamente da responsabilidade civil de entidades ou órgãos públicos, a Lei deixa ao intérprete a tarefa de proceder à integração do sistema protetivo.

A Constituição da República traz a teoria da responsabilidade objetiva, na modalidade do risco administrativo, no art. $37, \S 6^{\circ}$ (BRASIL, 1988).

À mingua de regramento específico sobre a matéria, deve-se admitir a invocação da referida norma para ensejar a responsabilização do Estado por atos lícitos e ilícitos, sob o 
fundamento de que, no âmbito do Estado Democrático de Direito, toda a atuação jurisdicional se submete ao próprio Direito, sendo referido dispositivo princípio geral da responsabilidade civil do Estado.

Doutrina majoritária defende se tratar de teoria a permitir a adoção de causas excludentes da responsabilidade do Estado, quais sejam, culpa da vítima, culpa de terceiros, caso fortuito ou força maior, sendo afastada a teoria do risco integral, que não admite tais excludentes (CARVALHO FILHO, 2007, p. 498-499).

De forma majoritária, admite-se, ainda, a aplicação da Responsabilidade Objetiva na hipótese de ato comissivo (ação). Há divergência existe, todavia, no que se refere aos atos omissivos, quando se aplica, para alguns autores, a Responsabilidade Subjetiva.

Doutrina mais conservadora afirma que quis o legislador constituinte originário prever o cabimento da regra do citado dispositivo apenas para os atos comissivos. Ao revés, outros doutrinadores afirmam a tese em sentido contrário, propugnando a aplicação da responsabilidade objetiva para atos comissivos e omissivos. A polêmica decorre da presença do verbo "causarem" na redação do artigo $37, \S 6^{\circ}$, da Constituição da República.

Segundo Luiz Carlos Figueira de Melo e José Luiz de Moura Faleiros Júnior:

No que diz respeito à dita divergência, de um lado, posiciona-se a corrente doutrinária capitaneada por Celso Antônio Bandeira de Mello, José dos Santos Carvalho Filho, Maria Sylvia Zanella di Pietro, Oswaldo Aranha Bandeira de Mello, Rui Stoco, dentre outros autores, que sustentam que a responsabilidade civil do Estado deve seguir a teoria subjetiva nas condutas omissivas, sendo imprescindível a comprovação do elemento culpa ('faute') para sua configuração. Numa outra vertente, minoritária, contrapondo-se à tese subjetivista, tem-se a corrente liderada por Hely Lopes Meirelles, Celso Ribeiro Bastos, Odete Medauar, Álvaro Lazzarini, Weida Zancaner Brunini, Yussef Said Cahali, dentre outros, advogando a tese de que o Estado, em face do disposto no artigo $37, \S^{\circ}$, da Constituição da República, deve responder objetivamente pelos danos causados a terceiros, seja por ação ou omissão, enfocando ambas as modalidades de conduta como possíveis causas do dano (FALEIROS JÚNIOR; MELO, 2019, p. 100).

A responsabilidade subjetiva é aquela originária da Administração pelo mau funcionamento do serviço, funcionamento retardado ou em razão da sua inexistência, cuja decorrência deve ser concretamente avaliada e analisada. De acordo com José dos Santos Carvalho Filho:

A teoria foi consagrada pela clássica doutrina de Paul Duez, segundo a qual o lesado não precisaria identificar o agente estatal causador do dano. Bastava-Ihe comprovar o mau funcionamento do serviço público, mesmo que fosse impossível apontar o agente que o provocou. A doutrina, então, cognominou o fato como culpa anônima ou falta do serviço (CARVALHO FILHO, 2007, p. 489).

Nessas hipóteses, trata-se de responsabilidade subjetiva, uma vez que fundada na culpa anônima do serviço. É mister acentuar que apenas se presume a culpa do Estado quando o serviço funcionou tardiamente ou não funcionou (ANDRADE, 2005, p. 29).

Vale consignar que para aqueles que entendem que a responsabilidade estatal é sempre objetiva, independentemente de ter sido causada por ação ou omissão estatal, a responsabi- 
lidade para os atos, ainda que lícitos, deve considerar a solidariedade social ou princípio da igualdade.

A solidariedade social (ou princípio da igualdade) é para compensar eventual desigualdade criada pela própria atividade estatal e se justifica na medida em que todos os membros devem concorrer para a reparação do dano. Discorre sobre esta hipótese Celso Antônio Bandeira de Melo:

\begin{abstract}
Com efeito: a ordem jurídica pode prever e prevê o eventual contraste entre dois interesses, ambos valiosos e ambos merecedores de tutela e proteção. Prevê igualmente solução nestes casos. Se um interesse público não pode ser satisfeito sem o sacrifício de um interesse privado, também tutelado, a solução normativa ditará a preponderância do primeiro, nos casos em que deva prevalecer, sem, contudo, ignorar ou menoscabar a proteção do interesse privado a ser atingido. Estabelece-se, então, um dever de indenizar àquele cujo direito foi sacrificado a fim de poder-se realizar outro interesse maior. Vale dizer: opera-se uma conversão do direito atingido em sua equivalente expressão patrimonial (MELO, 2003, p. 853).
\end{abstract}

Por outro lado, para aqueles doutrinadores que diferenciam a aplicabilidade da responsabilidade subjetiva ou objetiva a depender tratar de atos omissivos ou comissivos, corrente com a qual se filia, é importante assinalar que as situações de funcionamento anormal ou funcionamento defeituoso do serviço público jurisdicional é hipótese de denegação da justiça, significando atividade estatal omissiva (DIAS, 2004, 195).

Nestes casos, deve-se defender a adoção da teoria subjetiva de responsabilidade, cunhada no direito francês, que está configurada a partir da culpa anônima do serviço público.

O mau funcionamento da justiça pode resultar da culpa de seu agente, determinado e individualizado, ou da culpa anônima, simples falta do serviço.

O acúmulo do trabalho, cujo ingresso não pode ser controlado, a insuperável falta de Juízes e servidores e a falta de segurança ou de recursos suficientes (inclusive tecnológicos) são fatores determinantes do funcionamento anormal, sem que se possa precisar aquele a quem se deve imputar a falta. Para o lesado, basta demonstrar a falha do serviço, o dano e o nexo causal.

O mau funcionamento corresponde à hipótese mais genérica de denegação da justiça. É caracterizada, normalmente, por uma ilegalidade processual que pode ocorrer em qualquer plano, por ação do agente no desempenho de função processual, do que serve de exemplo o excessivo cumprimento da pena (art. 5, LXXV, da Constituição) (AGUIAR JÚNIOR, 1993, p. 49-50).

Para os atos de caráter ativista, ainda que lícitos, a responsabilidade será objetiva, ocasião em que, como já defendido, deve se valer o intérprete da solidariedade social ou do princípio da igualdade. Neste ponto, vale ainda gizar que, para os atos lícitos, não é necessário individualizar o dolo ou a culpa.

Em suma, nas hipóteses de estudo propostas, a responsabilidade civil por ato decorrente da função jurisdicional, ainda que lícito, comissivo ou omissivo, é viável através do artigo $37, \S 6^{\circ}$ da $C R / 88$. No caso de ato comissivo, lícito ou ilícito (ocasião em que deve se valer o intérprete do princípio da igualdade), pela aplicação da teoria do risco administrativo, 
em caráter objetivo; no caso de ato omissivo e ilícito, pela aplicação da responsabilidade subjetiva por culpa administrativa (BRASIL, 1988).

Feitas essas considerações, o próximo passo será investigar atos jurisdicionais em que é passível a aplicação da teoria da responsabilidade civil do Estado.

Cumpre registrar, por relevante, que a teoria do Risco Administrativo, afinada à corrente majoritária da doutrinada já apresentada, defende que o nexo causal e consequentemente a responsabilidade civil do Estado não é estendida a qualquer caso em que haja comprovado o prejuízo, sendo possível desconsiderar o dever de indenizar quando estiverem presentes as excludentes de responsabilização.

$\mathrm{Na}$ hipótese de causas excludentes ou atenuantes da responsabilidade quanto aos atos judiciais, exemplifica Aguiar Júnior:

São causas exonerativas da responsabilidade do Estado: a) quando o dano decorre com exclusividade da ação dolosa ou culposa da parte (deixando de fazer prova, prestando esclarecimentos inexatos, omitindo-se nos atos a que deve comparecer, conluiando-se com a outra parte, induzindo testemunhas, retendo ou extraviando autos, deixando de praticar atos de seu dever, corrompendo os que participam da cena judiciária, etc.). Se há concorrência de culpas, a responsabilidade do Estado será atenuada na proporção de sua participação causal; b) decorrer o dano de má interpretação dada pelo Juiz à lei. Os conceitos indeterminados ('mulher honesta', 'motivo relevante', 'interesse público', etc.) e as cláusulas gerais (nestas devendo o Juiz estabelecer previamente qual a norma de conduta que deveria ter sido observada para o caso, como no art. 159 do CC), deixam ao Juiz largo espectro decisório, cuja opção deve ser admitida enquanto não arbitrária, isto é, enquanto fundamentada dentro do sistema jurídico vigente; c) resultar o dano de força maior, pois é uma causa estranha ao serviço, ordinariamente imprevisível em sua produção e sempre absolutamente irresistível. 0 caso fortuito, por ser um evento interno, diretamente conectado com o funcionamento do serviço mas com causa desconhecida, não isenta de responder o Estado pelo mau funcionamento do serviço. Enquanto na força maior a causa do dano é externa, inexistindo nexo de causalidade entre a ação do Juiz ou do serviço e o resultado, no caso fortuito a causa é a falta do serviço, ainda que desconhecida; d) ter sido o dano produzido por terceiro, cujo resultado não incumbia ao Estado evitar, nas circunstâncias do fato; e) o Estado de necessidade defensivo, quando o perigo foi criado pelo lesado, que assim sofre o dano resultante da ação necessária do Estado para afastar o perigo. Nos demais casos não há exclusão: '0 estado de necessidade pré-exclui a ilicitude, não a responsabilidade' (AGUIAR JÚNIOR, 1993, p. 51-52).

Esclarece-se que nas hipóteses de omissão quanto ao dever de prevenção e segurança em relação aos dados pessoais dos jurisdicionados, o presente estudo adota o posicionamento de que é aplicável a responsabilidade pela falta do serviço, que decorre do não funcionamento ou do funcionamento insuficiente, inadequado, tardio ou lento do serviço que o Judiciário deveria prestar.

Como ressaltado, a responsabilidade será objetiva para atos judiciais de caráter ativista, ainda que lícitos; será, contudo, subjetiva, para o caso de ato omissivo e ilícito, como o descrito acima. 
É imperioso gizar que a LGPD, em seu artigo $6^{\circ}$, prevê ainda que as atividades de tratamento de dados pessoais deverão observar a boa-fé e os princípios da segurança e da prevenção (BRASIL, 2018).

O primeiro princípio se refere à utilização de medidas técnicas e administrativas aptas a proteger os dados pessoais de acessos não autorizados e de situações acidentais ou ilícitas de destruição, perda, alteração, comunicação ou difusão; o segundo, prega a adoção de medidas para prevenir a ocorrência de danos em virtude do tratamento de dados pessoais (BRASIL, 2018).

A violação destes princípios deve permitir a configuração de dano moral ou material ao jurisdicionado passível de indenização quando o mau funcionamento do Judiciário lhe causou o dano grave.

Entretanto, defende-se que a situação danosa causada pelo exercício da função judicial lícita não pode implicar, necessariamente, uma responsabilidade solidária do Estado e do magistrado; antes, implica uma responsabilidade direta e exclusiva do primeiro, considerando a responsabilização do juiz apenas se, no exercício do seu munus, atue com dolo ou fraude.

Assim, o ato jurisdicional típico, se lesivo, deve empenhar a responsabilidade civil do Estado, prescindindo-se da configuração da responsabilidade pessoal do magistrado, que é mais restrita.

Isso porque deve ser restrita a possibilidade de responsabilização pessoal dos juízes pelos danos consequentes ao exercício da função jurisdicional, diante da preocupação em se resguardar sua imprescindível independência.

$\mathrm{Na}$ verdade, um certo grau de imunidade acaba se prestando a garantir ao magistrado o desempenho de suas funções com plena autonomia, em proveito dos jurisdicionados.

Mas, como já defendido, há de se buscar um equilíbrio entre essa independência e a chamada responsabilidade-controle e sanção perante a sociedade, de modo a permitir o direito ao ressarcimento.

Ademais, deve-se ressaltar que não se está aqui a defender que todo e qualquer ato de divulgação de dados pelo Judiciário seja condenável. Apenas diante do acentuado grau de violação dos direitos à privacidade e intimidade é que se deve permitir a responsabilização.

A título de exemplo, pode-se considerar o caso da criança de 10 anos que engravidou após ser sofrer uma série de estupros pelo tio, iniciados desde os seus 6 anos de idade, em São Mateus, no Espírito Santo.

Após o Tribunal de Justiça do Espírito Santo conceder à criança o direito previsto na lei de interromper a gravidez, movimentos conservadores buscaram informações no processo sobre onde a infante seria submetida ao procedimento para interromper a gestação. Seus dados pessoais também foram coletados e indevidamente divulgados nas redes sociais, 0 que culminou em protestos em frente ao hospital, chamando a vítima do crime de "assassina" (ANGELO, 2020).

É cediço que o artigo 17 do Estatuto da Criança e do Adolescente (ECA) prevê a inviolabilidade da integridade física, psíquica e moral da criança e do adolescente, o que abrange a 
prevenção da imagem, da identidade, autonomia, valores, ideias e crenças, espaços e objetos pessoais (BRASIL, 1990).

O estatuto também estabelece como dever da família, da comunidade e da sociedade em geral, especialmente do poder público, assegurar, com absoluta prioridade, a efetivação dos direitos referentes à vida, à saúde, à alimentação, à educação, ao esporte, ao lazer, à profissionalização, à cultura, à dignidade, ao respeito, à liberdade e à convivência familiar e comunitária (BRASIL, 1990).

No caso acima narrado, além do direito fundamental à proteção de dados pessoais, o direito ao respeito e à dignidade da criança foram violados com a divulgação das informações processuais e sigilosas.

Neste caso, também foram violados os princípios da segurança e da prevenção, que devem reger todas as atividades de tratamento de dados pessoais, porquanto a lei estabeleceu, em relação a esses delitos, como regra obrigatória, o segredo de justiça. 0 artigo 234-B do Código Penal enuncia que "os processos em que se apuram crimes definidos neste Título [Crimes Contra a Dignidade Sexual] correrão em segredo de justiça" (BRASIL, 1940).

Conforme lições de Julio Fabbrini Mirabete e de Renato N. Fabbrini sobre o artigo:

Embora a regra seja a da publicidade dos atos processuais, a Constituição Federal admite o sigilo necessário à defesa da intimidade (art. $5^{\circ}, \mathrm{LX}$ ) e o Código de Processo Penal autoriza a decretação do segredo de justiça para a preservação da intimidade, vida privada, honra e imagem do ofendido (art. $201, \S 6^{\circ}$ ). Nos crimes sexuais, além do dano decorrente da própria infração, havia de suportar a vítima, via de regra, também os malefícios da exposição pública de sua intimidade decorrente da instauração do processo penal. Com essa finalidade, a lei estabeleceu, em relação a esses delitos, como regra obrigatória, o segredo de justiça. Não se permite ao juiz, nesses casos, a mesma discricionariedade que lhe faculta a lei processual. Embora se refira a lei somente ao processo, o sigilo deve alcançar o inquérito policial, incumbindo à autoridade policial e ao juiz a adoção nos autos de providências necessárias à preservação da intimidade da vítima. (MIRABETE; FABBRINI p.1612).

Em casos deste jaez, em que a pessoa é identificada a partir de dados colhidos em processos jurisdicionais que deveriam correr sob sigilo, esta, ao sofrer diversos ataques da própria sociedade, como apontamentos preconceituosos, violação de seu direito à locomoção, de expressão, de participação, sofre dano grave passível de indenização.

Nestes casos, o preconceito e a discriminação deixariam à margem este indivíduo, o que somente foi possível a partir de um ato ilícito, ainda que omissivo do Estado, em relação ao registro do processo judicial e ao seu andamento, sendo passível a adoção da responsabilidade objetiva.

Presente, portanto, a relação de causa e efeito entre o comportamento estatal e o dano, o dano qualificado ("dano jurídico"), que ultrapassa os incômodos e sacrifícios razoáveis, toleráveis ou exigíveis pelo indivíduo.

Cumpre ressaltar que, no Estado Democrático de Direito, não se está autorizado a suprimir ou violar direitos fundamentais. A aplicação da responsabilidade no caso de violação à proteção de dados pela função jurisdicional é um importante instrumento de correção ou redução de injustiças e da violação aos princípios fundamentais do Direito. 
Portanto, é necessário definir o adequado cumprimento dos direitos dos cidadãos, compatibilizando-os com o interesse público de divulgação de dados em processos, principalmente diante da possibilidade de dano grave no caso de vazamentos ou divulgação de informações pessoais presentes em ações judiciais.

\section{CONSIDERAÇÓES FINAIS}

A eficiência do Judiciário a partir do uso da tecnologia depende de suplantar os desafios técnicos e jurídicos sobre privacidade e proteção de dados pessoais, permitindo maior adaptação dos institutos do processo à preocupante era virtual.

Trata-se de uma realidade complexa e dinâmica, que precisa ser entendida pelos operadores do Direito, atendendo aos direitos e princípios fundamentais da Constituição, o que somente é possível se forem consideradas a proteção de dados pessoais, a privacidade e a intimidade.

O presente trabalho apresenta como problema a aplicação da responsabilização pelo Estado em relação aos atos judiciais para além daqueles expressamente previstos no texto constitucional.

A responsabilidade civil por ato judicial comissivo ou omissivo, ainda que lícito, é viável através do artigo $37, \S 6^{\circ}$ da $\mathrm{CR} / 88$. No caso de ato comissivo, lícito ou ilícito (ocasião em que deve se valer o intérprete do princípio da igualdade), pela aplicação da teoria do risco administrativo, em caráter objetivo; no caso de ato omissivo e ilícito, pela aplicação da responsabilidade subjetiva por culpa administrativa.

Assim, presentes o nexo causal e o dano grave, deve ser permitido ao cidadão se utilizar de mecanismos jurídicos que possibilitem o ressarcimento.

A aplicação da responsabilidade no caso de violação à proteção de dados pela função jurisdicional é um importante instrumento de correção ou redução de injustiças e da violação aos princípios fundamentais do Direito.

Se por um lado é certo que o Estado não deve responder indiscriminadamente, também certo é que na hipótese de danos graves a sua responsabilização garante uma atuação com fulcro na proteção e no respeito aos direitos da coletividade na sociedade da informação.

De tudo o que foi dito, observa-se que argumentos de irresponsabilidade não justificam que o Judiciário se afigure, de forma isolada, do resto da organização estatal, em especial, diante da evolução e do aumento considerável de sua atuação na sociedade moderna.

Ademais, a partir das exigências do Estado Democrático de Direito, a regra deve ser a responsabilidade do Estado por danos decorrentes da prestação jurisdicional, sendo a irresponsabilidade a exceção. 


\section{REFERENCIAS}

ANDRADE, Érico. Responsabilidade civil do estado e o direito de regresso. São Paulo: IOB, 2005.

ANGELO, Tiago. Privacidade e Dignidade: Dados pessoais de criança que engravidou após estupro devem ser retiradas do ar. Conjur. 17 Ago. 2020. Disponível em: https://www.conjur.com.br/2020-ago-17/informacoes-crianca-engravidou-estupro-sair-ar Tiago Angelo. Acesso em: 24 ago. 2020.

ARAGÃO, Alexandre Santos de. Os fundamentos da responsabilidade civil do estado. Doutrinas Essenciais de Responsabilidade Civil. vol. 6, p. 63 - 76, Out. 2011.

BRANT, Cássio Augusto Barros. Marco Civil da Internet: comentários sobre a Lei 12.965/2014. Belo Horizonte: D'Plácido, 2014.

BRASIL. Decreto-lei $n^{\circ} 2.848$, de 07 de dezembro de 1940. Código Penal. Diário Oficial da União, Brasília, 31 Dez. 1940. Disponível em: http://www.planalto.gov.br/ccivil_03/decreto-lei/del2848compilado.htm. Acesso em: 22 jan. 2019.

BRASIL. Decreto-lei n 3.689, de 03 de outubro de 1941. Código de Processo Penal. Diário Oficial da União, Brasília, 13 Out. 1941. Disponível em: https://www2.camara.leg.br/legin/fed/declei/1940-1949/decreto-lei-3689-3-outubro-1941-322206-exposicaodemotivos-149193-pe.html. Acesso em: 22 jan. 2019.

BRASIL. Constituição (1988). Constituição da República Federativa do Brasil. Diário Oficial da União, Brasília, 05 Out. 1988. Disponível em: http://www.planalto.gov.br/ccivil_03/constituicao/constituicao.htm. Acesso em: 17 maio 2020 .

BRASIL. Lei nº. 8069, de 13 de julho de 1990. Dispõe sobre o Estatuto da Criança e do Adolescente e dá outras providências. Diário Oficial da União, Brasília, 16 Jul. 1990. Disponível em: http://www.planalto.gov.br/ccivil_03/ leis/18069.htm. Acesso em 04 ago. 2020.

BRASIL. Lei $n^{\circ}$. 8078, de 11 de setembro de 1990. Dispõe sobre a proteção do consumidor e dá outras providências. Diário Oficial da União, Brasília, 11 Set. 1990. Disponível em Http://www.planalto.gov.br/ccivil_03/Leis/ L8078.htm. Acesso em 04 mar. 2020.

BRASIL. Lei n ${ }^{\circ}$ 10.406, de 10 de janeiro de 2002. Institui o Código Civil. In: Diário Oficial daRepública Federativa do Brasil, Brasília, DF, 11 jan. 2002. Disponível em:

http://www.planalto.gov.br/ccivil_03/leis/2002/l10406.htm . Acesso em: 16 jul. 2020.

BRASIL. Lei n. 12.527, de 18 de novembro de 2011. Regula o acesso a informações previsto no inciso XXXIII do art. $5^{\circ}$, no inciso II do $\S 3^{\circ}$ do art. 37 e no $\S 2^{\circ}$ do art. 216 da Constituição Federal; altera a Lei no 8.112 , de 11 de dezembro de 1990; revoga a Lei $n^{\circ} 11.111$, de 5 de maio de 2005, e dispositivos da Lei $n^{\circ} 8.159$, de 8 de janeiro de 1991; e dá outras providências. Diário Oficial da União, Brasília, 18 nov. 2011.Disponível em: http://www.planalto. gov.br/ccivil_03/_ato2011-2014/2011/lei/l12527.htm. Acesso em: 2 mar. 2020.

BRASIL. Lei $n^{\circ}$ 12.965, de 23 de abril de 2014. Estabelece princípios, garantias, direitos e deveres para o uso da Internet no Brasil. Diário Oficial da União, Brasília, 24 Abr. 2014. Disponível em: http://www.planalto.gov.br/ccivil_03/_ato2011-2014/2014/lei/112965.htm. Acesso em: 17 mar. 2020.

BRASIL. Lei no 13.709, de 14 de agosto de 2018. Lei Geral de Proteção de Dados Pessoais. Diário Oficial da União, Brasília, 15 Ago. 2018a. Disponível em: http://www.planalto.gov.br/ccivil_03/_ato2015-2018/2018/lei/L13709. htm. Acesso em: 17 set. 2020.

BRASIL. Conselho Nacional de Justiça. Recomendação 73. Disponível em: https://atos.cnj.jus.br/atos/detaIhar/3432. Acesso em: 21 ago. 2020.

CAHALI, Yussef Said. Responsabilidade civil do Estado. 3. ed. rev., atual. eampl. São Paulo: RT, 2007.

CAPPELLETTI, Mauro; GARTH, Bryant. Acesso à justiça. Tradução de Ellen Gracie Northfleet. Porto Alegre: Sergio Antônio Fabris, 1988.

CAPPELLETTI, Mauro. Juízes Irresponsáveis?. Porto Alegre: Sérgio Antônio Fabris, 1989. 
CARVALHO, Ricardo Motta Vaz de. O impacto do processo judicial eletrônico no direito contemporâneo. In: Encontro Nacional do CONPEDI, 19., 2010, Fortaleza. Anais... Florianópolis: Fundação Boiteux, 2010, p. 4121-4133. Disponível em: http://www.publicadireito.com.br/conpedi/manaus/arquivos/anais/fortaleza/4128.pdf. Acesso em: 27 Jan. 2020.

CARVALHO FILHO, José dos Santos. Direito Administrativo. 10. ed. Rio de Janeiro: Lumen Júris, 2014.

CARVALHO FILHO, José dos Santos. Manual de Direito Administrativo. Rio de Janeiro: Lumen Júris, 2007.

CAVALIERI FILHO, Sérgio. Programa de Responsabilidade Civil. 7. ed. São Paulo: Atlas, 2007.

DERGINT, Augusto do Amaral. Responsabilidade do Estado por atos judiciais. RT, São Paulo: RT, ano 83, v. 710, p. 225-230, dez. 1994.

DIAS, Ronaldo Brêtas de Carvalho. Responsabilidade do Estado pela função jurisdicional. Belo Horizonte: Del Rey, 2004.

FALEIROS JÚNIOR, José Luiz de Moura; MELO, Luiz Carlos Figueira de. A responsabilidade civil objetiva do Estado por atos omissivos: realidade ou apenas tendência?. Revista Publicum. Rio de Janeiro, v. 5, n. 1, p. 92- 110, 2019.

FEIGELSON, Bruno; BECKER, Daniel. Acesso à justiça para além de Cappelletti e Garth: a resolução de disputas na era digital e o papel dos métodos online de resolução de conflitos (ODR) na mitigação da crise de justiça do Brasil. In: Direito, Processo e Tecnologia. $1^{\text {a }}$ ed. São Paulo: Thomson Reuters, Brasil, 2020, p. 203/218.

FRAZÃO, Ana. Fundamentos da proteção de dados pessoais- Noções introdutórias para a compreensão da importância da Lei Geral de Proteção de Dados. In: TEPEDINO, Gustavo; FRAZÃO, Ana; OLIVA, Milena Donato. Lei Geral de Proteção de Dados e suas repercussões no direito brasileiro. São Paulo: Thomson Reuters Brasil, 2019.

GONÇALVES, Carlos Roberto. Responsabilidade Civil. 8. ed. São Paulo: Saraiva, 2003.

HARARI, Yuval Noah. 21 Lições para o Século 21. Trad. Paulo Geiger. São Paulo: Companhia das Letras, 2018.

MACEDO, Marcus Paulo Queiroz. A responsabilidade civil em face de danos decorrentes de atos oriundos do poder judiciário. Revista de Direito Privado. São Paulo: RT, vol. 35, 2008.

MELO, Celso Antônio Bandeira de. Curso de Direito Administrativo. São Paulo: Malheiros, 2003.

MENDES, Gilmar Ferreira; COELHO, Inocêncio Mártires; BRANCO, Paulo Gustavo Gonet. Curso de Direito Constitucional. 4 ed. São Paulo: Saraiva, 2009.

MENDES, Laura. Decisão histórica do STF reconhece direito fundamental à proteção de dados pessoais. jota. info. Fonte: Jota: Disponível em: https://www.jota.info/opiniao-e-analise/artigos/decisao-historica-do-stf-reconhece-direito-fundamental-a-protecao-de-dados-pessoais-10052020\#_ftn13. Acesso em: 28 set. 2020.

MENDES, Laura. Habeas Data e Autodeterminação informativa: dois lados da mesma moeda. In: Direitos Fundamentais \& Justiça, ano 12, n. 39, p. 185-216, jul./dez. 2018.

MIRABETE, Julio Fabbrini; FABBRINI, Renato. Código Penal Interpretado. 8. ed. São Paulo: Atlas, 2012, p.1612.

MORAES, Maria Celina Bodin de. Risco, Solidariedade e Responsabilidade Objetiva. São Paulo: Revista dos Tribunais. Vol. 854, p. $11-37,2006$.

KRAMMES, A. G. Workflow em processos judiciais eletrônicos. São Paulo: LTr. 2010.

RACANICCI, J. (27 de maio de 2019). jota.info. Fonte: Jota: www.jota.info/justica/cnj-normas-dados-pessoais-tribunais-27052019. Acesso em: 28 set. 2020.

STF. (2018).Supremo Tribunal Federal: www.stf.jus.br/arquivo/cms/jurisprudencialnternacional/aneo/BJI5DIREITOAOESQUECIMENTO.pdf. Acesso em: set. 2020.

ROQUE, André. A tutela coletiva dos dados pessoais na lei geral de proteção de dados pessoais (LGPD). Revista Eletrônica de Direito Processual - REDP, Rio de Janeiro, ano 13, v. 20, n. 2, p. 1-19, maio/ago. 2019. Disponível em: https://www.e publicacoes.uerj.br/index.php/redp/article/view/42138/30270. Acesso em: 28 set. 2019.

SILVA, Daniele Maciel da. Responsabilidade Civil do Estado por Atos Judiciais no Brasil, Trabalho apresentado como parte do relatório do Programa Institucional de Iniciação Científica - PIBIC/CNPq. 2002/2003. 
SIMÃO FILHO, Adalberto; SCHWARTZ, Germano André Doederlein. Big Data em tempos de internet das coisas. In: PARENTONI, Leonardo (Coord.); GONTIJO, Bruno Miranda; LIMA, Henrique Cunha Souza (Orgs.). Direito, Tecnologia e Inovação. V. 1. Belo Horizonte: D'Plácido, 2018. Cap. 2.2, p. 217-246.

STOCO. Rui. Responsabilidade civil e sua interpretação jurisprudencial. São Paulo: Revista dos Tribunais, 1996.

STOCO. Rui. Responsabilidade civil do estado por obras que realiza. Doutrinas Essenciais de Responsabilidade Civil. Vol. 6. p. 605 - 638. Out. 2011.

STOCO. Rui. Tratado de Responsabilidade Civil: doutrina e jurisprudência. São Paulo: Revista dos Tribunais, 2014.

TAVARES, A. R. Curso de Direito Constitucional. 4. ed. São Paulo: Saraiva, 2006.

THEODORO JÚNIOR, H. Curso de direito processual civil - teoria geral do direito processual civil, processo de conhecimento e procedimento comum. 56. ed. Rio de Janeiro: Forense, 2015.

THEODORO JÚNIOR, H. et al. Novo CPC - Fundamentos e sistematização. Rio de Janeiro: Forense, 2015.

THIBAU, V. L. Teoria do processo democrático e técnica probatória. In: BRÊTAS, Ronaldo C. Dias; SOARES, Carlos Henrique. Técnica processual. Belo Horizonte: Del Rey, 2015.

VELLOSO, A. A. El garantismo procesal. Rosario: Editorial Librería Juris, 2010.

Recebido/Received: 15.10.2020.

Aprovado/Approved: 15.12.2020. 